\title{
TWO GREAT INTRICATE GESTATIONAL SYNDROMES. NEW SCREENING AND TREATMENT STRATEGIES
}

\begin{abstract}
GEORGETA GÎNFĂLEAN ${ }^{1}$
1 “Lucian Blaga” University of Sibiu

Keywords: gestational Abstract: Gestational hypertension and premature birth frequently and independently affect the hypertension, preeclampsia, premature birth, risk of recurrence, screening, prevention, calcium, low dose aspirin, probiotics, PAPP-A, sFlt, sEng-1, PGTF pregnancy prognosis with potentially detrimental influence of the pregnancy evolution. Pregnancyinduced hypertension, spectrum and categories of the systemic disease: gestational hypertension, preeclampsia, eclamsia, Hellp syndrome, overlapping preeclampsia (PE) chronic arterial hypertension, are some of the complications that can occur over the pregnancy evolution. Annually, preeclampsia affects approximately 4 million pregnancies. According to ACOG, preeclampsia complicates the evolution of pregnancies in a 2-8\% ratio. According to WHO and FIGO, premature birth occurs after 37 weeks of complete amenorrhea (AS) (or 259 days of amenorrhea). A spontaneous premature birth complicates about 5-18\% of pregnancies. I emphasize that the two gestational syndromes are intricate because 1/4 -1/3 of premature births are associated with preeclampsia. Considered to be an important public health problem, it is important to identify new methods of evaluation, screening and therapy for gestational syndromes, taking into account the risk of increased recurrence of child birth in a subsequent pregnancy.
\end{abstract}

Gestational hypertension and premature birth, both independently and adversely affect the prognosis of pregnancy, with potential detrimental influence in the following three sections: maternal, placental and fetal, due to the systemic nature of the hypertensive condition.(1)

Pregnancy-induced hypertension, with the spectrum of subcategories of this systemic disease: gestational hypertension, preeclampsia, eclampsia, Hellp Syndrome, preeclampsia overlapping with chronic hypertension, and recent Posterior reversible encephalopathy syndrome (PRES), are some of the complications that can occur during pregnancy.

The definition of Preeclampsia coincides internationally, the criteria being standardized in goog practice guides. Criteria for preeclampsia are considered: Systolic BP > $140 \mathrm{mmHg}$ or Diastolic BP $>90 \mathrm{mmHg}$, first occurring during pregnancy, after a gestational period of 20 weeks of amenorrhea in a previously normotensive patient.

Another diagnostic criterion is proteinuria $>0.3 \mathrm{~g} / 24$ hours or albumin/creatinine ratio urinary $>0.3$, or qualitative test- dipstick $1+$, followed by albumin/ creatinine urinary ratio (a ratio of 0.3 confirms proteinuria and requires quantitative testing by proteinuria $/ 24 \mathrm{~h}$ ). Proteinuria should be evaluated in the first trimester of pregnancy for pre-existing renal impairment damage, followed by a screening pre-eclampsia after 20 weeks of gestation.(2)

Preeclampsia affects approximately 4 million pregnant women worldwide. According to ACOG, preeclampsia has an incidence of about $2-8 \%, 5-7 \%$ are nulliparous and $2 \%$ of patients will develop eclampsia. $(3,4)$

Preeclampsia along with the other subcategories of this hypersensitive disease spectrum are responsible annually for approximately 400,000 maternal deaths and six million perinatal fetal deaths while being considered risk factors for premature birth and underweight newborns.

According to The International Federation of Gynecology and Obstetrics (FIGO) and the World Health Organization (WHO), premature birth is the one that occurs before 37 weeks of complete amenorrhea (AS) or 259 days of amenorrhea.

Premature birth is a multifactorial pathology, it can occur spontaneously ( $2 / 3$ of cases do not have an identified risk factor, and $1 / 3$ have risk factors such as preeclampsia, nulliparity, male gender, cervical-isthmic incompetence, prematurely ruptured membranes, installed premature labor) or iatrogenic, mandatory for the maternal-fetal indications. The most common maternal indication for a full-term pregnancy is preeclampsia, the most common fetal indication is intrauterine growth restriction (IUGR) with Doppler changes suggestive of fetal distress.(5)

WHO classifies premature birth into the following chronological categories: extreme ( $<28$ weeks of gestation), moderate ( $<28$ weeks of gestation and $<32$ weeks of gestation), late $>32-36$ weeks 6 days).(6)

Premature birth is the most important cause of mortality and perinatal morbidity worldwide, with an increasing incidence. Spontaneous premature birth complicates $5-18 \%$ of pregnancies. We emphasize that the two gestational syndromes are intricate because $1 / 4-1 / 3$ from premature births is associated with preeclampsia. A pregnancy with a positive background of premature births and preeclampsia represents a risk factor in the evolution of subsequent pregnancies. In premature births, epidemiological studies show that the risk is 4 times higher in the pregnant woman that has had a premature birth in the past, and the risk is twice the number of cases if the

${ }^{1}$ Corresponding author: Georgeta Gînfălean, Str. Moreni, Nr. 19, Sibiu, România, E-mail: ginfalean.georgeta@yahoo.com, Phone: +04723 254897 Article received on 04.08 .2020 and accepted for publication on 24.08.2020 


\section{CLINICAL ASPECTS}

parturient sister gave birth prematurely, outlining a possible family aggregation.(7)

In the case of Preeclampsia, the risk of recurrence at a later pregnancy is increased, especially in case of nulliparous with early onset of preeclampsia ( $<30$ weeks gestation) has a $40 \%$ risk of recurrence.(8)

\section{Preeclampsia with early- versus late-onset}

Preeclampsia is classified into two subcategories according to the chronological criterion, of early or late-onset compared to 34 weeks of gestation, having both clinical implications for recognition of the spectrum of hypertensive disease, as well as in understanding the underlying pathophysiological mechanism.

\section{Preeclampsia early-onset, $<\mathbf{3 4}$ weeks gestation:}

It has a frequency of $20-30 \%$ but is associated with the highest premature birth rate and morbidity, respectively maternal-prenatal mortality. The pathophysiologic mechanism of this subtype is represented by the incomplete transformation of the spiral arteries, resulting in an abnormal, altered placenta, leading to hypoperfusion, leading to trans-placental reduced nutrient exchanges to the fetal area, subsequently causing restriction of intrauterine fetal growth (RCFIU). The main changes in the Doppler study occur at the level of the umbilical cord's artery, with rapid progression, of the diastolic flow who is not reversible.(9) Also, elevated levels of two antiangiogenic mediators (sFit-1, sEng) are presented, which correlate with the increase in vascular resistance in the uterine arteries.

Early preeclampsia is characterized by an antigenic imbalance reflected by an increased ratio $>$ sFit-1 / PIGF (platelet crest factor). It is common in this subtype of preeclampsia proteinuria, with elevated levels (table no. 1).

Preeclampsia with late-onset, $>34$ weeks gestation: It has a frequency of $80 \%$ of cases of preeclampsia and it generally develops without damage in the placental or fetal section.

Table no. 1. Important characteristics of preeclampsia with early-onset - versus late

\begin{tabular}{|c|c|c|}
\hline Characteristics & $\begin{array}{c}\text { Preeclampsia } \\
\text { erly- onset }\end{array}$ & $\begin{array}{l}\text { Preeclampsia } \\
\text { late-onset }\end{array}$ \\
\hline $\begin{array}{l}\text { Gestational period } \\
\text { (weeks) at the time } \\
\text { of diagnosis }\end{array}$ & $<34$ & $>34$ \\
\hline Placentation & abnormal & normal \\
\hline $\begin{array}{c}\text { Degree of } \\
\text { remodeling of spiral } \\
\text { arterioles }\end{array}$ & abnormal & $\begin{array}{c}\text { Predominantly } \\
\text { Degree of infusion } \\
\text { restriction at the villous } \\
\text { level }\end{array}$ \\
\hline sFlt - 1 & $\begin{array}{c}\text { Values raised } \\
\text { early }\end{array}$ & Values raised late \\
\hline PIGF & $\begin{array}{c}\text { Values raised } \\
\text { early }\end{array}$ & Values raised late \\
\hline Prognosis & yes & no \\
\hline Prevention & $\begin{array}{l}\text { Low dose aspirin } \\
\text { (75-150mg) } \\
\text { Daily from } 16 \\
\text { weeks }\end{array}$ & $\begin{array}{c}\text { Induction/Birth at } 37 \\
\text { weeks or when the } \\
\text { diagnosis is established } \\
>37 \text { weeks }\end{array}$ \\
\hline $\begin{array}{l}\text { Gestational age at } \\
\text { birth }\end{array}$ & Premature & Premature/term \\
\hline $\begin{array}{l}\text { Newborn weight at } \\
\text { birth }\end{array}$ & $\begin{array}{c}\text { RCFIU } \\
\text { SGA } \\
\text { (underweight } \\
\text { newborn) }\end{array}$ & $\begin{array}{c}\text { Normal } \\
\text { LGA } \\
\text { (overweight newbown) }\end{array}$ \\
\hline Degree of hypoxia & ++ chronic & + acute \\
\hline $\begin{array}{c}\text { Adaptation to } \\
\text { hypoxia }\end{array}$ & Systemic/gradual & Aimed CNS/rapid \\
\hline $\begin{array}{c}\text { Tolerance to } \\
\text { hypoxia }\end{array}$ & high & low \\
\hline Doppler Alteration & Early onset & Late onset \\
\hline
\end{tabular}

\begin{tabular}{|c|c|c|}
\hline & Rapid progression & Slow progression \\
\hline Neonatal prognosis & Increased & Low morbidity and \\
& morbidity and & mortality \\
& mortality & Subsequent \\
& Immediate & cardiovascular disease \\
& unfavorable & \\
& prognosis & \\
\hline
\end{tabular}

By comparing the two subtypes (table no. 1) from an epidemiological point of view, the following conclusions can be drawn:

- The maternal morbidity rate is double in the subgroup with early onset of preeclampsia (12,2\% versus $5.5 \%)$.

- The group with early onset of preeclampsia associated an increased incidence in changes in Doppler in the uterine arteries, underweight fetuses, fetal death in the uterus, fetuses with APGAR score 7 to 5 minutes, immediate death in the neonatal period.

- Fetuses from the subgroup with late-onset preeclampsia were at increased risk of subsequent cardiovascular disease, and those from the early onset subgroup presented an immediate unfavorable perinatal prognosis.

Considered to be an important public health issue, an attempt was made to identify new methods of assessment and screening of gestational syndromes, given the risk of increased recurrence of the child-bearer that had a positive medical history.

That is why we consider it necessary to identify early obstetrical risk factors (chronic hypertension, obesity, anemia), delimitation of the group of pregnant women at risk of preeclampsia, by early identification of favorable factors: environmental (cold, humidity, excessive work etc.), dietary factors (protein $<$ vitamin deficiencies, hypercaloric diet etc.), the presence existing of vascular or kidney disorders in a previous pregnancy.(10)

Screening for preeclampsia in the first trimester of pregnancy shows the identification rate of preeclampsia before 37 weeks with an accuracy of $77 \%$ : mean arterial pressure (MAP) assessment, Doppler assessment of uterine arteries ( index pulsatility,) maternal serum levels of PAPP-A and PIGF. Still under development, but with a possible impact in the future, there is the ratio of serum biomarkers sFit-1/PIGFT, thus improving the diagnostic approach, management and prognostic performance, especially in the forms of preeclampsia with earlyonset.(11)

The Fetal Medicine Foundation (FMF) proposes a similar evaluation algorithm of the two gestational syndromes, to detect the pregnant group of women that were at high risk of developing preeclampsia with premature onset. The items proposed in the evaluation of the case are nulliparity, gestation period 11-14 weeks of gestation, maternal mean blood pressure, maternal serum level PAAP-A, PIGF, sFlt-1 biomarkers, the average value of the pulsatility index at the level of the uterine artery. FMF concludes that positive nulliparous to this algorithm in the first trimester of pregnancy has an increased risk of developing preeclampsia with early-onset and other severe placental complications throughout pregnancy.

About 1 in 10 pregnant women identified as having an increased risk according to the FMF algorithm will develop at least one severe placental-mediated complication.(12)

In a Scandinavian cohort study performed on 70,149 single fetal pregnancies, administering probiotics from the early gestation period significantly reduced the risk of spontaneous premature birth or induced pregnancy.(13) Premature births before $<34$ weeks, especially $<32$ weeks, are closely associated with intrauterine infections, with ascending transmission from the vaginal level, with sequelae in the most severe neonatal population, some even neurological. 


\section{CLINICAL ASPECTS}

Bacterial vaginosis, characterized by diminished or absent lactobacillus flora and compensatory colonization of anaerobe or facultative anaerobe microorganism (Gardnerella vaginalis, Prevotella $\mathrm{sp}$, Bacteroide $\mathrm{sp}$, Mobiluncus sp, grampositive cocci, and genital mycoplasma: Mycoplasma hominis and Ureaplasma urealyticm) increases the risk of premature birth before 34 weeks. Trials performed in this regard with antibiotics have not established their effectiveness, which is why studies have been performed by repopulating the local microbiome with probiotics to treat genitourinary infections, especially bacterial vaginosis, with promising results.

The vagina that is colonized by lactobacilli produces $\mathrm{H} 2 \mathrm{O} 2$, which limits the development of vaginosis. Maintaining vaginal $\mathrm{pH}+4$, due to the production of lactic acid and $\mathrm{H} 2 \mathrm{O} 2$, is essential for a vaginal physiological microbe, thus preventing a potential premature birth. In this study, they administered 2 capsules per day (each capsule containing over 1 million lactobacilli), for 6-12 weeks, up to 24-25 weeks of gestation of Lactobacillus rhamnosus GR-1 and Lactobacillus reuteri RC14.(14)

In the prevention of premature births, we mention progesterone supplementation and transvaginal cervical measurements to establish the maintenance of the pregnancy hormone therapy (vaginal or oral). Calcium supplementation ( $>$ $1 \mathrm{~g}$ /day, respectively $1.2-2 \mathrm{~g} /$ day in case of low calcium diet) has been associated with a significant reduction in the risk of preeclampsia and premature birth.

Daily administration of low-dose aspirin (74-150mg), starting at 14.16 weeks of gestation, reduces the risk of preeclampsia by $10 \%$ while reducing the risk of premature birth by $14 \%$. Aspirin's mechanism of action: salicylic acid converts to Tomboxane (via cyclooxygenase) by platelets, without alteration of prostacyclin production (prostaglandin 12, with vasodilating effect). Low dose aspirin prevents the production of thromboxane $\mathrm{A} 2$ in the placenta and platelet, thus decreasing vasoconstrictor and vascular formation.

Another role of a low dose aspirin is to decrease thrombin tissue production, which promotes fibrinolysis.Medical therapy for preeclampsia is symptomatic in some pathogenic cases, but the etiological treatment of this condition is the actual birth, by interruption of the pathogenetic chain, it is desirable to be done at an opportune maternal-fetal moment. $(15,16)$

Pregnancy-related hypertension along with other subcategories of the systemic disease (including preeclampsia) remains a major cause of mortality and maternal-fetal morbidity.(18)

Linkages between the two great gestational syndromes: pre-eclampsia and premature birth serve to underscore the importance of efforts to investigate and understand the biologic mechanism(s) underlying the pathogenesis of both pregnancy disorders.

Hopefully, using serum biomarkers for prevention and with specific treatment modalities, we can reduce future cardiovascular disease in the mothers, make motherhood as safe as possible and reduce the number of affected fetus developing hypertension and cardiovascular disease later in the adult life.(17-19)

\section{REFERENCES}

1. Collier $\mathrm{CH}$, Martin JN. Preterm parturition and preeclampsia: The confluence of two great gestational syndromes. International Journal Gynecology and Obstetrics; 2020 DOI: 10.1002/ijgo.13173.

2. Societatea de Obstetrică și Ginecologie din România (SOGR). Hipertensiunea asociată sarcinii, Ghid clinic 2019 SOGR, https://sogr.ro/ghiduri-clinice-2019. Accessed on
12.05.2020.

3. Umesawa M, Kobashi G. Epidemiology of hypertensive disorders in pregnancy: Prevalence, risk factors, predictors and prognosis. Hypertens Res. 2017;40:213-220.

4. Nagalla SR, Janaki V, et al. Glycosylated fibronectin point-of-care test for diagnosis of pre-eclampsia in a low-resource setting: a prospective Southeast Asian population study. BJOG. 19 May 2020 https://doi.org/10.1111/1471-0528.16323.

5. Societatea de Obstetrică şi Ginecologie din România (SOGR). Nașterea înainte de termen, Ghid clinic 2019 SCORG, https://sogr.ro/ghiduri-clinice-2019.Accessed on 05.05.2020

6. World Health Organization - Preterm birth, https://www.who.int/preterm-birth. Accessed on 16.05.2020.

7. Peltecu Gh. Tratat de chirurgie, Editia a II-aEditura Academiei Române, București; 2014.p. 436.

8. Williams Obstetrics 24 th edition, Obstetrical Complications, Hypertensive Disorders, Counseling for future pregnancies; 2014. p. 768.

9. Muresan D, Rotar IC, Stamatian F. The usefulness of fetal Doppler evaluation in early versus late onset intrauterine growth restriction. Review of the literature. Med Ultrason. 2016;18:103-109.

10. Stretean A. Obstetrică Patologică, Universitatea „Lucian Blaga"; 1997. p. 259.

11. Herraiz I. New pathways to diagnose pre-eclampsia, BJOG. https://obgyn.onlinelibrary.wiley.com/doi/epdf/10.1111/14 71-0528.16405.

12. Boutin A, Guerbz P, Gasse C. Tapp S, Bujold E. Pregnancy outcomes in nulliparous women with positive firsttrimester preterm preeclampsia screening test: The Great Obstetrical Syndromes (GOS) cohort study, DOI: https://doi.org/10.1016/j.ajog.2020.08.008.

13. Mahsa N, Jacobsson B. Timing of probiotic milk consumption during pregenancy and effects on the incidence of preeclampsia and preterm delivery, A prospective observational cohort study in Norway, BMJ Open. 2018;8:e018021.

14. Krauss S, et al. Reproductive Health 2010, 7:14 http://www.reproductive-healthjournal.com/content/7/1/14, Study protocol Randomized controlled trial of probiotics for the prevention of spontaneous preterm delivery associated with intrauterine infection: study protocol.

15. Stretean A. Obstetrică Patologică, Universitatea „Lucian Blaga; 1997.p. 260.

16. Duhig K, Vandermolen B, Shennan A. Recent advances in the diagnosis and management of pre-eclampsia, F1000Res, 2018;7:242.

17. Anouk B, Teunissen PW, Constantijn F, et al. Effect of early-onset preeclampsia on cardiovascular risk in the fifth decade of life. Am J Obstet Gynecol. 2017;216:523.e1523.e7.

18. Bertagnolli M, Luu TM, Lewandowski AJ, Leeson P, Nuyt AM Preterm birth and hypertension: Is there a link? Curr Hypertens Rep. 2016;18:28.

19. Lewandowski AJ, Leeson P. Preeclampsia, prematurity and cardiovascular health in adult life. Early Human Dev. 2014;90:725-729. 